Article

\title{
Numerical Simulation and Experimental Investigation on Electron Beam Welding of Spray-Formed 7055 Aluminum Alloy
}

\author{
Shaogang Wang ${ }^{1, *}$, Zheng Wang ${ }^{1}$, Chengcong Zhang ${ }^{2}$ and Zhiguo Wang ${ }^{2}$ \\ 1 College of Materials Science and Technology, Nanjing University of Aeronautics and Astronautics, \\ Nanjing 211106, China; helpeole@126.com \\ 2 Shanghai Aerospace Equipments Manufacturer Co., Ltd., Shanghai 200245, China; \\ jason9999991@sina.com (C.Z.); 17754869389@163.com (Z.W.) \\ * Correspondence: sgwang@nuaa.edu.cn; Tel.: +86-025-5211-2900
}

Received: 24 September 2020; Accepted: 15 October 2020; Published: 20 October 2020

\begin{abstract}
The spray-formed 7055 aluminum alloy is welded by electron beam welding. Combined with the numerical simulation of a welding temperature field, the effect of different welding procedures on the microstructure and mechanical properties of welded joints is investigated in this study. Results show that the joints with good properties can be obtained under proper welding procedures. The microstructure analysis demonstrates that the fusion zone mainly consists of equiaxed grains, while a fine equiaxed grain zone is formed near the fusion line. There are mainly $\alpha(\mathrm{Al}), \mathrm{MgZn}_{2}$, $\mathrm{Al}_{2} \mathrm{CuMg}$, and $\mathrm{Mg}_{32}(\mathrm{Al}, \mathrm{Zn})_{49}$ phases in the weld metal. The morphology of the weld can be improved by modification welding after the first bead welding, which is also advantageous to the mechanical properties of a welded joint. In the as-welded condition, compared with that of the base metal, the hardness of the weld zone decreased to a certain extent. The maximum tensile strength of a welded joint reaches $371.7 \mathrm{MPa}$. There are many dimples on the tensile fracture surface of a welded joint, and it dominantly presents the characteristic of ductile fracture. The simulated molten pool is consistent with the experimental weld morphology, and the reliability and accuracy of the simulation analysis are verified.
\end{abstract}

Keywords: 7055 aluminum alloy; electron beam welding; numerical simulation; microstructure; mechanical properties

\section{Introduction}

With the rapid development of the aerospace industry, structural materials with high performance are increasingly required. The 7000 series aluminum alloys have excellent comprehensive properties, such as low density, high tensile strength and high toughness, and good antifatigue and corrosion resistance [1,2]. They are widely used in many industry fields, such as aerospace, rail transportation, military equipment, etc. The 7055 aluminum alloy belongs to the Al-Zn-Mg-Cu series; it has high tensile strength due to the strengthening phases such as $\eta^{\prime}\left(\mathrm{MgZn}_{2}\right)$ and $\mathrm{S}\left(\mathrm{Al}_{2} \mathrm{CuMg}\right)$ precipitated in an $\mathrm{Al}$ matrix $[3,4]$. Compared with that by the traditional casting process, when the 7055 alloy is prepared by the spray-forming process, its mechanical property could be further improved $[5,6]$. This is because that the cooling rate is rapid during spray forming, the segregation of alloying elements is greatly reduced, and the fine strengthening phases are precipitated and uniformly distributed in the Al matrix.

In the industrial application, the welding process is often used to fabricate the structural components of aluminum alloys. Consequently, investigation on the welding of $\mathrm{Al}-\mathrm{Zn}-\mathrm{Mg}-\mathrm{Cu}$ alloys has been given more attention [7]. The existing results showed that the weldability of $\mathrm{Al}-\mathrm{Zn}-\mathrm{Mg}-\mathrm{Cu}$ alloys was poor; welding defects such as solidification cracking and gas pores were easily generated in 
the welded joints [8,9]. At present, the main welding methods for Al-Zn-Mg-Cu alloys involve metal inert gas (MIG) arc welding, laser beam welding (LBW), laser-MIG hybrid welding, and friction stir welding (FSW).

Peng et al. [10] investigated the MIG welding of the 7020 aluminum alloy. Their results showed that the addition of a welding wire containing the element $\mathrm{Zr}$ was advantageous to the formation of $\beta^{\prime}\left(\mathrm{Al}_{3} \mathrm{Zr}\right)$ particles in weldment; the $\beta^{\prime}$ particles could effectively pin dislocations and inhibit recrystallization of base metal $(\mathrm{BM})$, which was beneficial to the tensile strength of a welded joint. Balasubramanian et al. [11] found that the equiaxed grain was finer in the AA7075 MIG joint due to the employment of pulsed current, and thus the resistance to fatigue crack growth in a welded joint increased.

Hassan et al. [12] investigated the FSW of the AA7010-T7651 alloy, and the effect of rotational speed and travel speed on the microstructure and mechanical properties of a welded joint was discussed. An underwater FSW of the Al-Zn-Mg-Cu alloy was carried out in [13]. Results showed that water cooling could improve the weld thermal cycle during welding; the Guinier Preston II (GPII) zone was generated, and many strengthening phases such as $\mathrm{MgZn}_{2}$ were retained in the welded joint. As a result, compared with that of the traditional FSW joint, the tensile strength of an underwater FSW joint increased about $30 \%$. Although the possible defects in a fusion welding process will not appear during FSW process, it is difficult to weld the component with a complex shape by FSW due to the lack of process flexibility.

The LBW of Al-Zn-Mg-Cu alloys has been conducted in a number of studies. Ola and Doern [14] found that the laser beam welded joint with good performance could be obtained through preheating and the addition of a cold welding wire. Enz et al. $[15,16]$ used the conventional Nd:YAG laser and the enhanced $\mathrm{Yb}$ fiber laser to weld $\mathrm{Al}-\mathrm{Zn}-\mathrm{Mg}$-Cu alloys respectively. Results showed that the width of the weld by the enhanced $\mathrm{Yb}$ fiber laser welding increased slightly, but the gas pores caused by the collapse of the keyhole were greatly reduced. Holzer et al. [17] found that, in the welding of the AA7075 alloy, the hot cracking susceptibility was reduced with the decrease of welding speed. During laser-MIG hybrid welding, the absorption of laser energy increased due to the interaction between the MIG arc and laser beam. Hu and Richardson [18] investigated the laser-MIG hybrid welding of the AA7075 alloy, and the welding defects such as undercut were greatly reduced.

Electron beam welding (EBW) has the characteristics of high energy density, high depth-to-width ratio of weldment, a narrow heat-affected zone (HAZ), etc. Moreover, the active metals such as aluminum alloys can be well protected by the vacuum environment during EBW, and thus a welded joint with good quality can be obtained. Zhan et al. [19] investigated the LBW and EBW of the 5A06 aluminum alloy; their results showed that the cross-sectional area of the EBW joint was about $60 \%$ of that of LBW joint, but the tensile strength of the EBW joint was 1.3 times of that of LBW joint.

At present, there are a few reports on the EBW of Al- $\mathrm{Zn}-\mathrm{Mg}-\mathrm{Cu}$ alloys. In the present work, the spray-formed 7055 aluminum alloy is welded using EBW. The effect of different welding procedures on the microstructure and mechanical properties of welded joints are systematically investigated. Some results can be regarded as a guidance for the welding of the 7000 series aluminum alloys in the engineering application.

\section{Material and Experimental Procedure}

The base metal (BM) is the spray-formed 7055-T73 aluminum alloy with a thickness of $4 \mathrm{~mm}$, and its chemical composition is as follows (wt.\%): $8.2 \mathrm{Zn}, 2.2 \mathrm{Mg}, 2.1 \mathrm{Cu}, 0.13 \mathrm{Fe}, 0.12 \mathrm{Zr}, 0.09 \mathrm{Si}, 0.03 \mathrm{Cr}$, $0.05 \mathrm{Ti}$, and the balance Al. The BM was machined to the dimensions of $100 \mathrm{~mm} \times 50 \mathrm{~mm} \times 4 \mathrm{~mm}$ samples. The sample surface is thoroughly cleaned before welding. The butt joint was used, and the TETA-6E800M2 type electron beam welding machine (TETA LLC, Tomsk, Russia) was used to weld the samples along the longitudinal direction. During welding, the pressure of the vacuum chamber was $5 \times 10^{-3} \mathrm{~Pa}$, while the acceleration voltage was $60 \mathrm{kV}$, and working distance was $300 \mathrm{~mm}$. In order to improve the fluidity of molten pool and decrease the susceptibility to weld porosity, the circular 
electron beam scanning was added during welding. The scanning frequency was $500 \mathrm{~Hz}$, and scanning amplitude was $1 \%$. In addition, in the welding of aluminum alloy, formation defects such as undercut and concavity are easily generated. Consequently, as a contrast, modification welding was conducted to some samples after the first bead welding. The welding parameters are listed in Table 1.

Table 1. Electron beam welding parameters of 7055 alloy.

\begin{tabular}{ccccc}
\hline & Sample Number & Electron Beam Current (mA) & Focusing Current (mA) & Welding Speed (mm/s) \\
\hline \multirow{2}{*}{1} & First bead welding & 12.0 & 599 & 8 \\
& Modification welding & - & - & - \\
2 & First bead welding & 13.5 & 599 & - \\
& Modification welding & - & - & 9 \\
3 & First bead welding & 13.5 & 599 & 10 \\
& Modification welding & 9.5 & 579 & 10 \\
4 & First bead welding & 15.0 & 599 & - \\
& Modification welding & - & - & 10 \\
& First bead welding & 15.0 & 599 & 10 \\
\end{tabular}

After welding, the analytical sample was cut from the welded joint. The metallographic sample was then ground and polished successively, then it was etched with a Keller reagent. An MM6 type optical microscope (OM, Leica Microsystems Ltd, Wetzlar, Germany) was used to observe the microstructure of the welded joint. The phase constituent of the weld metal was identified by using a D8 Advance X-ray diffractometer (XRD, Bruker AXS GmbH, Karlsruhe, Germany). The substructure of the weldment was analyzed by using an JEM-2100F type transmission electron microscope (TEM, JEOL Ltd., Tokyo, Japan). Microhardness of the weld zone was measured by using an HXS-1000A type microhardness testing machine (Shanghai Highwell Opto-electronic Technology Ltd., Shanghai, China) with a load of $200 \mathrm{~g}$ and a duration time of $15 \mathrm{~s}$. According to the standard GB/T 2651-2008/ISO 4136:2001, the tensile tests of the welded joints were carried out at room temperature by using a CMT-5105 type electronic universal material testing machine (Ji'nan Meitesi Testing Technology Co., Ltd, Ji'nan, China), and the loading rate was $1 \mathrm{~mm} / \mathrm{min}$. The fracture morphology of the welded joint was observed by using Quanta 200 type scanning electron microscope (SEM, FEI Company, Hillsboro, OR, USA).

\section{Numerical Simulation on Welding Temperature Field}

The software MSC.Marc (MSC.Marc 2016, MSC Software Corporation, Newport Beach, CA, USA) was used to simulate the welding temperature field of the 7055 alloy. Firstly, it is necessary to choose a suitable heat source model. During the EBW of the 7055 alloy, the BM was locally melted, and the keyhole effect was generated in the molten pool. In the numerical simulation of EBW, a 3D body heat source model or the combined heat source model is often used. Compared with that of the single surface heat source model, both the energy absorption along the depth direction of weldment and the keyhole effect are fully considered by the combined heat source model during welding. In order to simulate accurately the morphology of molten pool during EBW, a combined heat source model made up of Gaussian surface heat source and 3D conical body heat source were used [20,21]. In the present work, surface heat source was used to simulate the thermal effect of the workpiece surface, and the 3D conical body heat source was used to simulate the keyhole effect.

During welding, besides the heat transfer inside the workpiece, the heat exchange between the workpiece and the surrounding environment should be considered. In the vacuum EBW process, there is almost no heat convection between the workpiece surface and ambient atmosphere, and thus the effect of heat radiation is mainly considered. The effect of heat radiation could be described by the following equation [21]:

$$
q_{1}=-\varepsilon \sigma\left[\left(T_{\mathrm{s}}+273\right)^{4}-\left(T_{0}+273\right)^{4}\right]
$$


where $\varepsilon$ is the heat emissivity; $\sigma$ is the Stefan-Boltzmann constant, which has a value of $5.67 \times 10^{-8} \mathrm{~W} /\left(\mathrm{m}^{2} \cdot \mathrm{K}^{4}\right) ; T_{\mathrm{S}}$ is the temperature of workpiece surface; and $T_{0}$ is the ambient temperature $\left(20{ }^{\circ} \mathrm{C}\right)$.

Due to the geometric symmetry of the welding sample, only one side of the welded joint was considered in the finite element model. In order to improve the calculation efficiency and accuracy, the small element mesh was used near the fusion zone (FZ), while the large element mesh was far from the FZ. From the weld center to the base metal, the unit size of the transition region was gradually varied. The total number of units was 41617, and the total number of nodes was 50622 .

The thermal properties of the 7055 alloy at a low temperature can be obtained by testing or by consulting the relevant literature, but it is difficult to acquire its thermal properties at a high temperature. In the present work, the JMatPro software (JMatPro 7.0, Sente Software Ltd., Guildford, UK) was used to calculate the thermal physical properties of the 7055 alloy at a high temperature, and the corresponding results are shown in Figure 1.

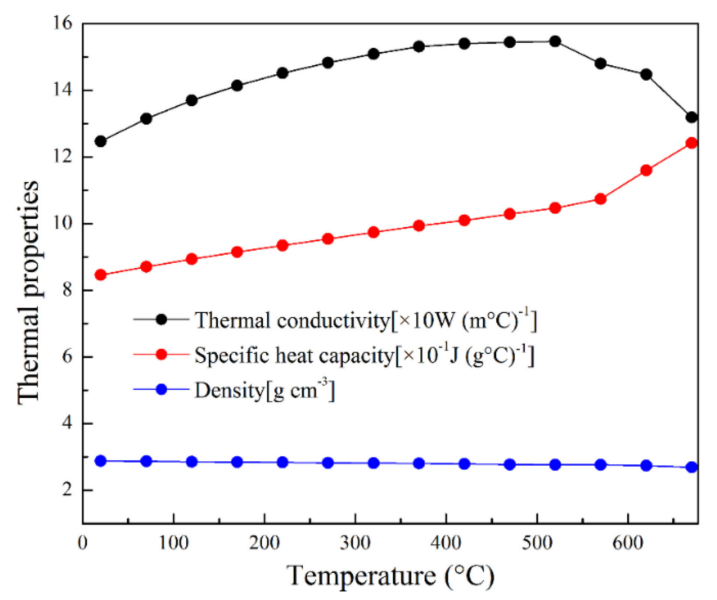

Figure 1. Thermal properties of 7055 alloy.

\section{Results and Discussion}

\subsection{Macrograph}

Figure 2 exhibits the appearance of the weld; joint 4 without modification welding is shown in Figure $2 \mathrm{a}$, and joint 5 with modification welding is shown in Figure $2 \mathrm{~b}$. It can be seen that both of the two joints are well formed, and no welding defects such as microcracks and gas pores are generated. Compared with that of the joint 4, although the weld width of joint 5 increased slightly, the weld surface is smooth and continuous, which indicates that the morphology of the weld can be improved to a certain extent by modification welding.
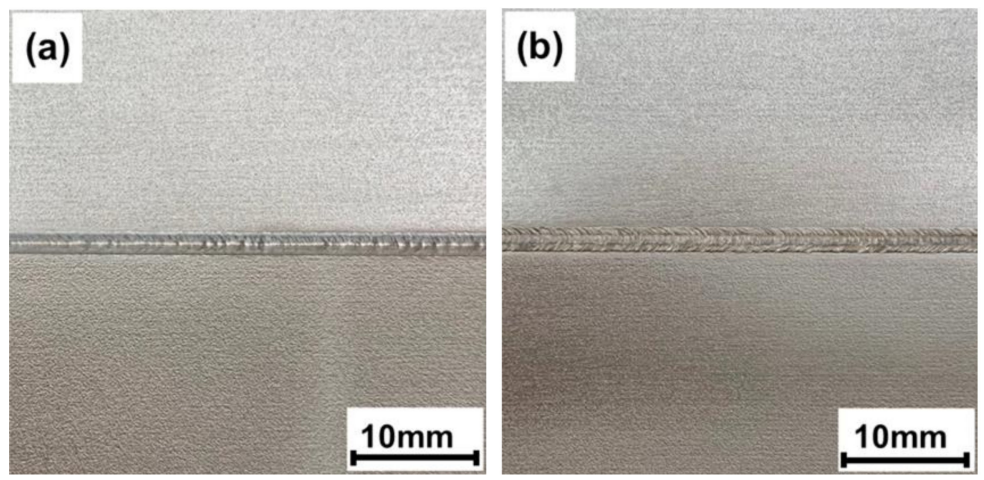

Figure 2. Appearance of weld: (a) joint 4 and (b) joint 5 . 


\subsection{Microstructure}

The microstructure of transition zone of joint 4 without modification welding is shown in Figure 3. Figure $3 b$ is the local magnification image near the fusion line (FL). The FZ is composed of equiaxed grains, and the fine precipitates uniformly distribute along grain boundaries. Owing to the effect of the weld thermal cycle, grains grow up in the HAZ, and the average of grain size is $24.3 \mu \mathrm{m}$. There are some particle phases within grains, and they become coarser near the FL.
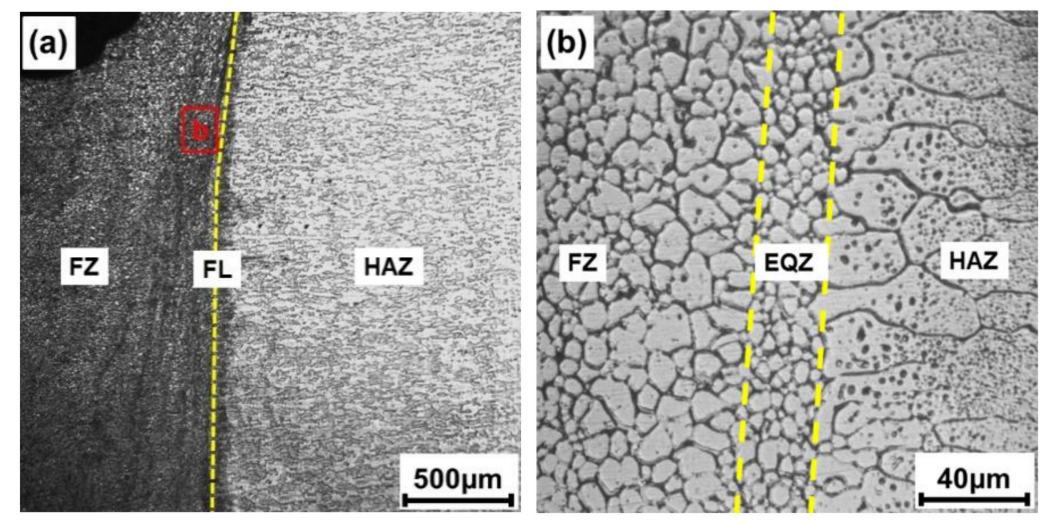

Figure 3. Microstructure of the joint transition zone without modification welding: (a) low magnification, and (b) high magnification.

There is a fine equiaxed grain zone (EQZ) with a width of about $20 \mu \mathrm{m}$ along the FL, as shown in Figure 3b. The reason for the formation of the EQZ is as follows: (1) During welding, the $\mathrm{Al}_{3} \mathrm{Zr}$ particles are easily aggregated in this region due to the temperature condition and the fluidity of the molten pool near the FL. The $\mathrm{Al}_{3} \mathrm{Zr}$ particle has high stability, which can act as the site of heterogeneous nucleation. (2) Elements $\mathrm{Zn}$ and $\mathrm{Mg}$ are enriched in the front of the liquid-solid interface. Due to the rapid crystallization rate and the large degree of constitutional supercooling, it was favorable to have the formation of fine equiaxed grains [22,23].

The microstructure of the transition zone of Joint 5 with modification welding is shown in Figure 4. As shown in Figure 4a, grain morphology in the lower part of joint 5 is basically the same as that in joint 4 , but there is a remelted region in the upper part of joint 5 . As shown in Figure $4 \mathrm{~b}$, the microstructure of the transition zone of joint 5 is different from that of joint 4 (Figure $3 \mathrm{~b}$ ). The width of the EQZ increased by about $40 \mu \mathrm{m}$, and the average of grain size is $3.6 \mu \mathrm{m}$. A columnar crystal is formed in FZ, and the precipitates within the grains decreased slightly in the HAZ.
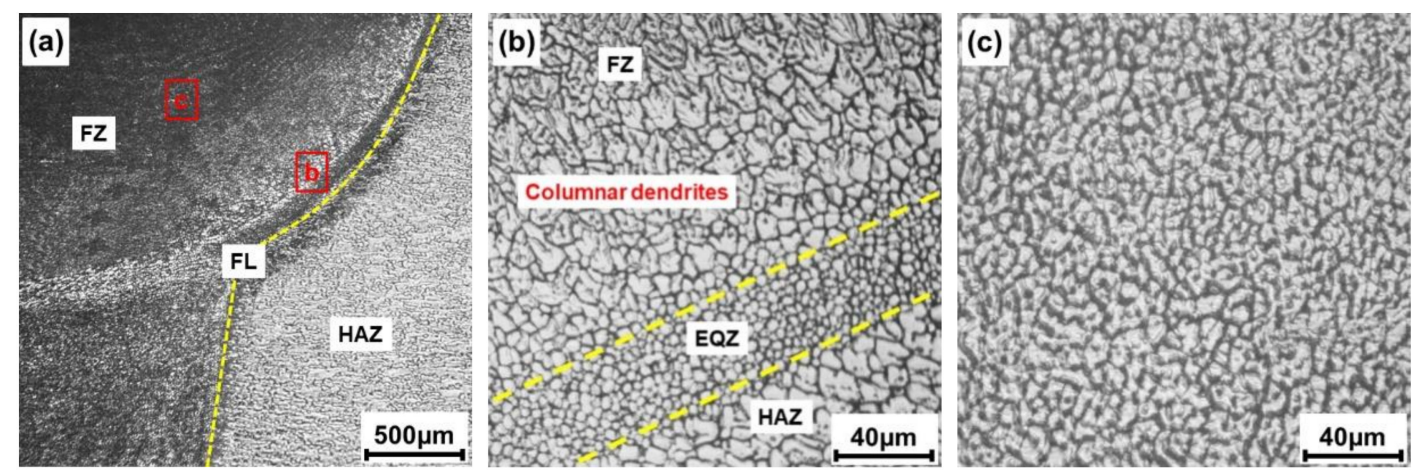

Figure 4. Microstructure of joint transition zone with modification welding: (a) low magnification, (b) high magnification, and (c) the modification welding zone.

Compared with the morphology of joint 4 (Figure 3a), the upper part of joint 5 (Figure 4a) presents a semicircular shape. Solute elements such as Zr are easily aggregated along the FL, and the fine 
equiaxed grains are formed by heterogeneous nucleation. With the formation of the EQZ and the release of crystallization latent heat, it was difficult to meet the condition of constitutional supercooling. From the FL to the FZ, the solidification rate gradually increased. The columnar crystals are formed between the FL and FZ. With the growth of columnar crystal, some solute elements enter the center of the molten pool. At this time, the degree of constitutional supercooling is large enough to form the equiaxed crystal. In the modification welding zone, the average of the grain size is $6.7 \mu \mathrm{m}$, as shown in Figure 4c.

An XRD analysis on the weldment of joint 4 is shown in Figure 5. There are mainly $\alpha(\mathrm{Al}), \mathrm{MgZn}_{2}$, $\mathrm{Al}_{2} \mathrm{CuMg}$, and $\mathrm{Mg}_{32}(\mathrm{Al}, \mathrm{Zn})_{49}$ phases in the $\mathrm{FZ}$. The $\beta^{\prime}\left(\mathrm{Al}_{3} \mathrm{Zr}\right)$ phase has coherent relation with the $\mathrm{Al}$ matrix, and both of them have the face-centered cubic structure. Moreover, the lattice parameter of $\mathrm{Al}_{3} \mathrm{Zr}(a=0.4051-0.4071 \mathrm{~nm})$ is close to that of $\mathrm{Al}(a=0.4049 \mathrm{~nm})$, which made the diffraction peaks of the two phases overlap during the XRD analysis. Consequently, it is difficult to identify the $\beta^{\prime}$ phase from $\alpha(\mathrm{Al})$ matrix. The 7055 alloy belongs to an age-hardening aluminum alloy. Due to the rapid cooling rate, the weld metal (WM) is underaging in the as-welded (AW) condition, and the quantity of strengthening phases in weldment is low. In order to promote the precipitation of strengthening phases in WM, the appropriate post weld heat treatment (PWHT) should be done to the welded joint. The relevant work will be carried out subsequently.

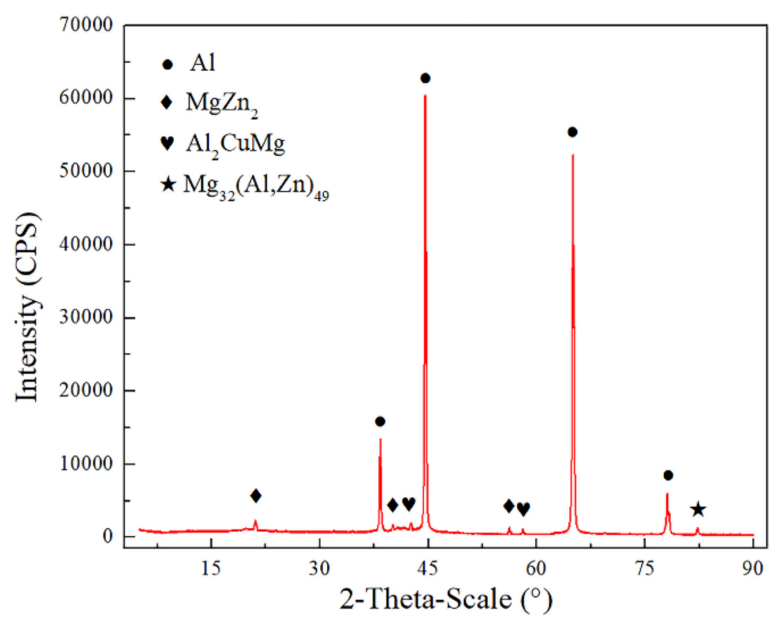

Figure 5. X-ray diffraction pattern of weldment.

An TEM analysis was carried out to the substructure of the weldment. Owing to the high temperature in the FZ during EBW, some alloying elements such as Zn and Mg were probably evaporated from molten pool, which led to the decrease of strengthening phases in the weldment. As shown in Figure 6a, the quantity of precipitates is low in the FZ. Figure 6b shows that the eutectic structure is generated at grain boundaries to form liquation film. Stress concentration is easily produced in this region, and it becomes the weak area of the welded joint. The bright field image of the HAZ adjacent to the FZ (near-HAZ) is shown in Figure 6c. Because this region is near the molten pool, its peak temperature exceeds the solidus temperature of the 7055 alloy, which is high enough to result in the dissolution of $\eta^{\prime}$ and $\eta$ phases. The precipitation sequence of secondary phase in the 7055 alloy during the aging process was as follows: supersaturated solid solution (SSS $\alpha) \rightarrow$ GP zone $\rightarrow$ $\eta^{\prime}$ metastable phase $\rightarrow \eta$ stable phase $\left(\mathrm{MgZn}_{2}\right)$ [24]. In the stages of cooling and natural aging, a small amount of GP zone and $\eta^{\prime}$ phase were precipitated in the near-HAZ. In addition, some spherical $\mathrm{Al}_{3} \mathrm{Zr}$ particles were generated in this region; these have an $\mathrm{L}_{2}$ structure and have coherent relation with the Al matrix. These particles could inhibit the recrystallization of aluminum alloy due to its pinning effect [25]. The bright field image of the HAZ adjacent to the BM (far-HAZ) is shown in Figure $6 \mathrm{~d}$. Most of the strengthening phases were retained in the original BM; only some $\eta^{\prime}$ phases were transformed into $\eta$ phases, and the strength of this region was slightly lower than that of the BM. 

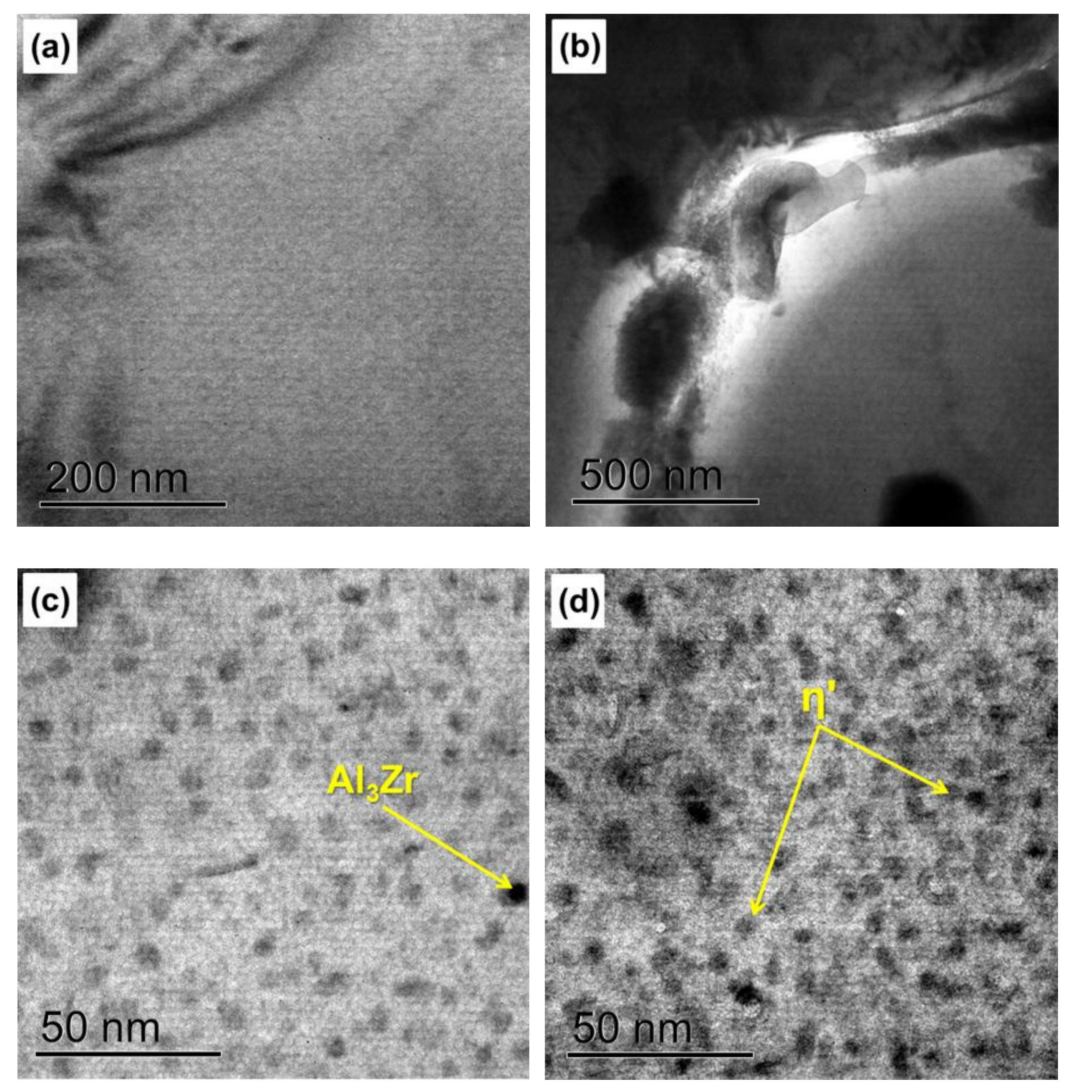

Figure 6. Transmission electron microscope (TEM) images of weldment: (a) within the grain in the fusion zone (FZ), (b) grain boundary in the FZ, (c) near heat-affected zone (HAZ), and (d) far-HAZ.

\subsection{Microhardness}

At a distance of $1.5 \mathrm{~mm}$ away from the top surface of weldment, the microhardness of the weld zone was measured along the direction that is perpendicular to weld center, and the spacing between two points was about $0.1 \mathrm{~mm}$. The hardness distribution curves of joints $2,3,4$, and 5 are shown in Figure 7a. They are approximately symmetrical to the weld center. Compared with that of the BM $(201 \mathrm{HV})$, the average hardness in the FZ decreased to $128 \mathrm{HV}$. In the near-HAZ, the hardness was $183 \mathrm{HV}$.
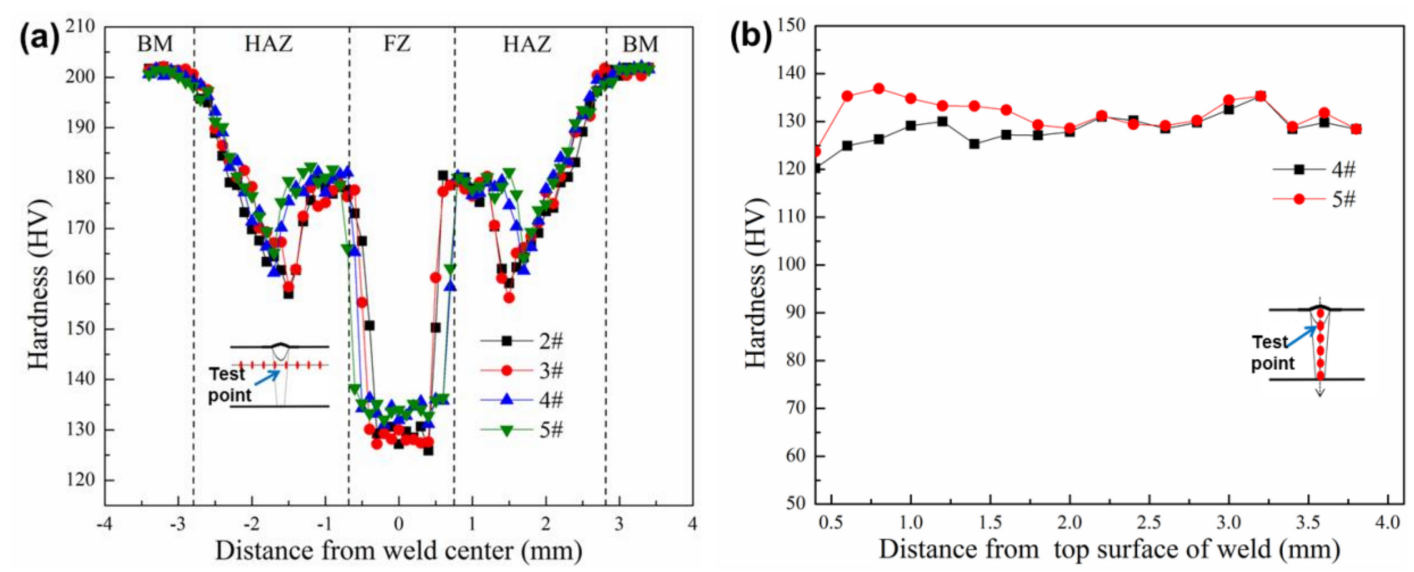

Figure 7. Microhardness distribution of welded joints: (a) perpendicular to the weld center and (b) parallel to the weld center. 
Precipitation strengthening is the primary mechanism in Al- $\mathrm{Zn}-\mathrm{Mg}-\mathrm{Cu}$ alloys. In AW condition, the WM was underaging due to the rapid cooling rate. The quantity of strengthening phases is low in the FZ, thus the hardness in FZ is the lowest. The hardness increased rapidly near the FL, which is attributed to the formation of EQZ. Owing to the effect of the weld thermal cycle, the grains grew larger, and the strengthening phases were aggregated in the HAZ. As a result, the hardness in the HAZ was lower than that of the BM [26].

As shown in Figure 7a, the hardness in the HAZ gradually decreased to $160 \mathrm{HV}$, and then it increased to that of the BM. This is because when the temperature was between the complete dissolution temperature and the initial dissolution temperature of the $\eta$ phase, many $\eta$ phases were still retained. The quantity of the GP zone and the $\eta^{\prime}$ phase in the Al matrix decreased to a certain extent after cooling. Compared with those of the GP zone and $\eta^{\prime}$ phase, the $\eta$ phase here is coarser, and it has incoherent relation with the $\mathrm{Al}$ matrix; therefore, the strengthening effect is weakened. The lowest hardness is related to the quantity of the $\eta$ phase. With the continuous decline of the temperature, when it was between the dissolution temperature of the $\eta$ phase and the transition temperature of $\eta^{\prime}$ to $\eta$ phase, the quantity of the dissolved $\eta^{\prime}$ phase gradually decreased, and thus the hardness increased to that of the BM.

Modification welding was not carried out for joints 2 and 4, while joints 3 and 5 underwent modification welding. The weldment of joints 3 and 5 was a bit wider, and its hardness was increased to about $7 \mathrm{HV}$. In order to analyze the effect of modification welding on the hardness of the weld zone, the hardness of joints 4 and 5 was measured along the direction that is parallel to the weld center, and the spacing between the two points was about $0.2 \mathrm{~mm}$. As shown in Figure $7 \mathrm{~b}$, in the upper part of the joint, the average hardness of joint 5 is $135 \mathrm{HV}$, which is higher than that of joint 4 (128 HV). In the lower part of the joint, the effect of modification welding gradually decreased, and thus the hardness of the two joints is basically the same.

\subsection{Tensile Strength and Fracture Analysis}

The results of the tensile tests of BM and welded joints are shown in Table 2. The date in Table 2 is the average of three measurements. The tensile strength of BM is $568.0 \mathrm{MPa}$ and its elongation is $8.1 \%$. As for the joints without modification welding, the tensile strength of joint 4 is $354.6 \mathrm{MPa}$, and joint 1 has the minimum tensile strength due to incomplete penetration, at only 267.1 MPa. Modification welding was carried out for joint 5, and its tensile strength reached $371.7 \mathrm{MPa}$, which is $65.4 \%$ of that of the BM. This is the maximum tensile strength of all joints under the experimental condition. It is obvious that the mechanical performance of welded joint improved after modification welding. Compared with that of the BM, the tensile strength of welded joint decreased to a certain extent. It is because that the quantity of strengthening phases in FZ is low in the AW condition. The FZ becomes the weak area of the welded joint, and all joints fail in weldment during stretching.

Table 2. Results of tensile tests of welded joints and base metal (BM).

\begin{tabular}{ccccccc}
\hline Sample Number & BM & Joint 1 & Joint 2 & Joint 3 & Joint 4 & Joint 5 \\
\hline Tensile strength (MPa) & 568.0 & 267.1 & 324.7 & 348.3 & 354.6 & 371.7 \\
Elongation (\%) & 8.10 & 1.19 & 1.88 & 1.91 & 1.87 & 2.12 \\
\hline
\end{tabular}

The fracture morphology of joint 4 without modification welding is shown in Figure 8a. The characteristics of ductile and brittle fractures are exhibited in the fracture surface. In the middle part of the fracture, some tearing ridges, cleavage facets, and secondary cracks appear, as shown in Figure 8c. In the lower part of the fracture, as shown in Figure 8e, fine equiaxed dimples distribute uniformly, which results from the connection and growth of micropores during stretching. In general, joint 4 presents the mixed mode of ductile and brittle fracture. 

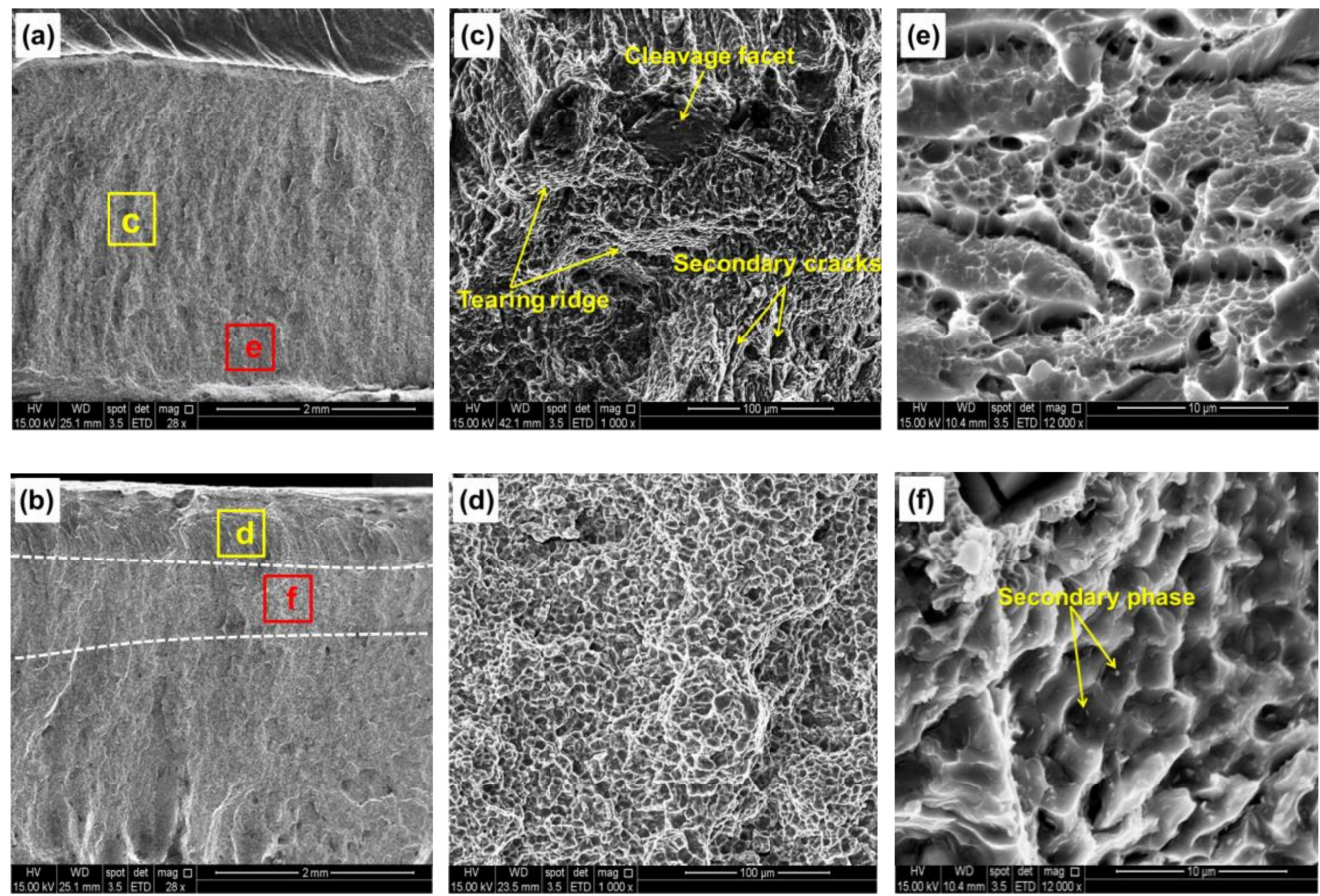

Figure 8. Tensile facture morphologies of welded joints: (a) joint 4, (b) joint 5, (c) magnification of yellow rectangle $\mathrm{c}$ in $(\mathbf{a})$, (d) magnification of yellow rectangle $\mathrm{d}$ in $(\mathbf{b}),(\mathbf{e})$ magnification of red rectangle e in (a), and (f) magnification of red rectangle $f$ in (b).

The fracture morphology of joint 5 with modification welding is shown in Figure $8 \mathrm{~b}$. The fracture can be further divided into three regions due to the effect of modification welding. The lower part of the fracture is basically the same as that of joint 4 . However, in the upper part of the fracture, as shown in Figure 8d, it shows the morphology of a typical transgranular fracture, which indicates that modification welding is advantageous to the mechanical performance of welded joint. As shown in Figure 8f, there are large dimples and secondary phases on the fracture surface, and the plasticity of the welded joint improved to a certain extent by modification welding.

\subsection{Numerical Simulation Analysis}

During welding, the weld thermal cycle has great effect on the formation of the weld. The distribution of the welding temperature field is simulated by a finite element analysis. The reliability and accuracy of simulation results can be verified by a comparison between the simulated molten pool and experimental weld morphology. Figure $9 a, b$ shows the welding temperature field under the condition of without modification welding or with modification welding, respectively. In the course of simulation calculation, the welding parameters correspond to those of joint 4 and joint 5 in Table 1. From Figure 9, it can be seen that the calculated weld morphologies are well consistent with the experimental ones. According to the mechanical properties of the welded joints, as shown in Table 2, joint 5 has maximum tensile strength. Consequently, the optimized welding parameters are determined as follows: electron beam current $15 \mathrm{~mA}$, focusing current $599 \mathrm{~mA}$, and welding speed $10 \mathrm{~mm} / \mathrm{s}$. 


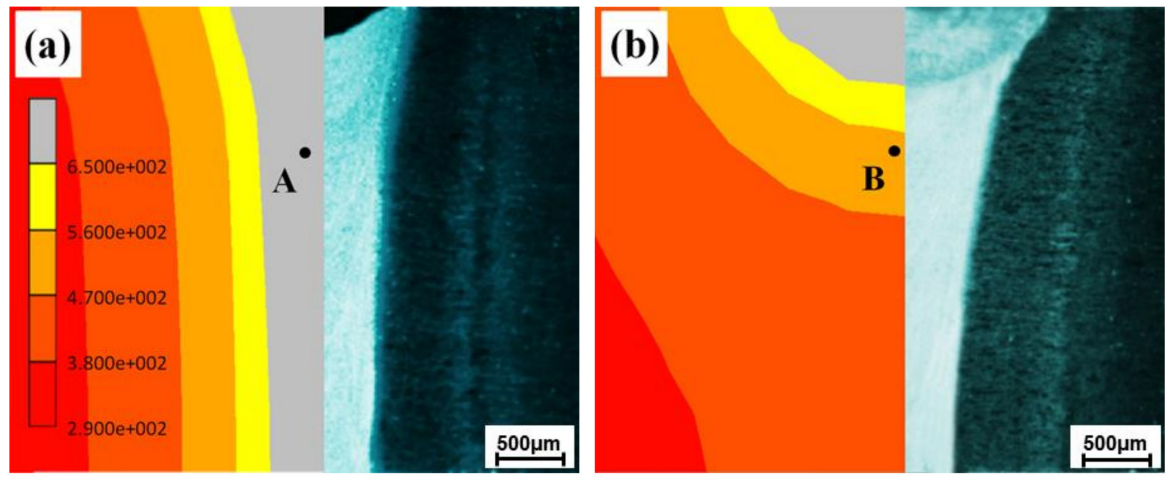

Figure 9. Comparison between simulated molten pool and experimental weld morphology: (a) without modification welding and (b) with modification welding.

The 7055 alloy is a typical age-hardening aluminum alloy, and it has high tensile strength due to the effect of precipitation strengthening. During welding, the temperature field distribution under a quasi-steady state is shown in Figure 10. The temperature of the weld center was about $1300^{\circ} \mathrm{C}$. The boiling points of elements $\mathrm{Zn}$ and $\mathrm{Mg}$ were $907^{\circ} \mathrm{C}$ and $1107^{\circ} \mathrm{C}$, respectively [27]. Some alloying elements $\mathrm{Zn}$ and $\mathrm{Mg}$ were probably evaporated from the molten pool during welding, which resulted in the decrease of strengthening phases in weldment. Consequently, compared with that of the BM, the tensile strength of the welded joint decreased to a certain extent, as given in Table 2. In addition, according to the theory of heat transfer, when the electron beam heat source with Gauss distribution is employed to the workpiece, the isotherm with a certain pattern will be formed on the cross-section of the weld. Combined with the effect of thermal buoyance and Marangoni convection, the distribution of alloying elements and grain size in weldment were greatly influenced by the welding temperature field [28]. Finally, the EQZ was formed near the FL, as shown in Figures $3 b$ and $4 b$.

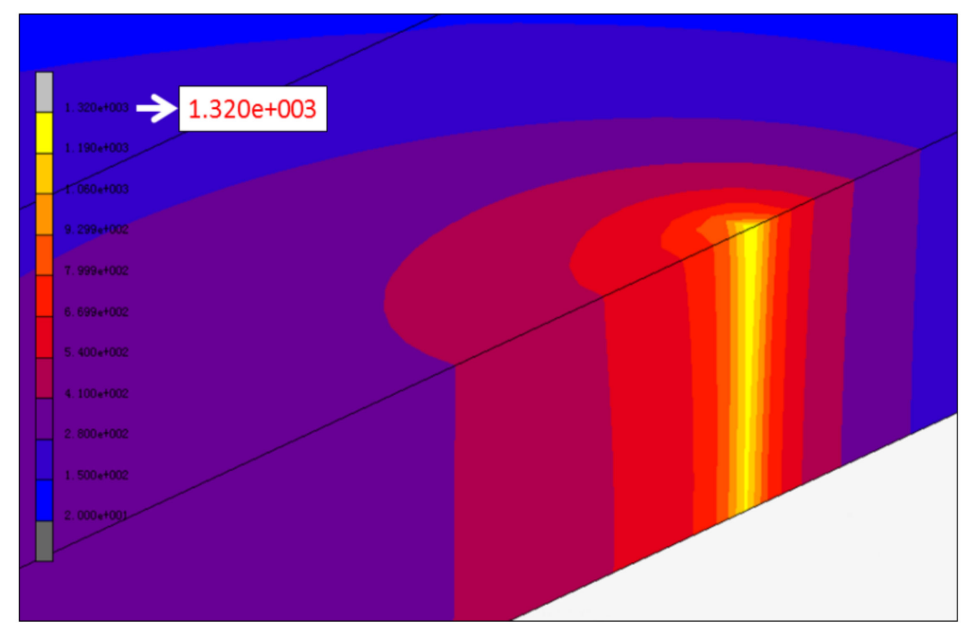

Figure 10. Temperature field distribution of 7055 alloy joint by electron beam welding (EBW).

The weld thermal cycle curves of point A in Figure $9 a$ and point B in Figure $9 b$ are shown in Figure 11. As for the joint 5 , the upper part of the weldment is influenced by modification welding, which is equivalent to a short-time remelted treatment. The cooling rate of joint 5 with modification welding is lower than that of joint 4 without modification welding. The dwelling time at high temperature for joint 5 is relatively long during welding. It is advantageous to have hydrogen escaping from the molten pool by remelting, and thus the weld porosity can be greatly reduced. It is obvious that the morphology and microstructure of the welded joint were improved by modification welding. Consequently, the mechanical properties of welded joint were improved to a certain extent. 


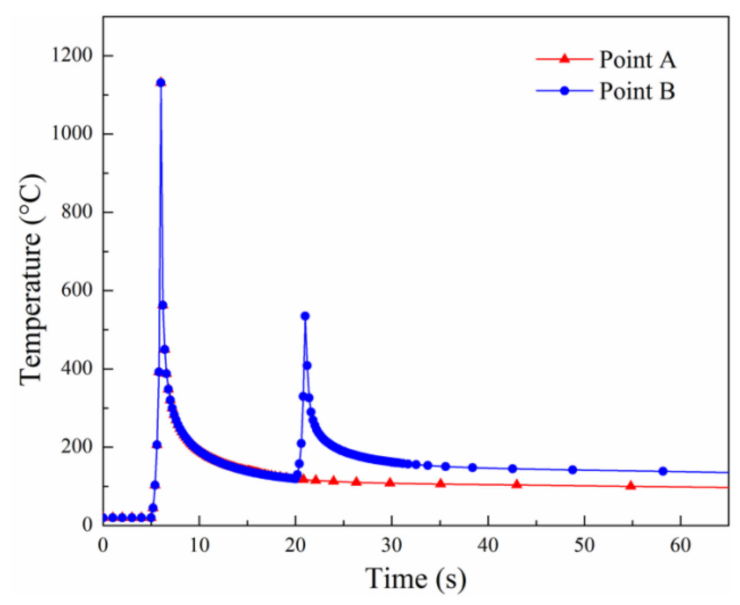

Figure 11. Weld thermal cycle curves of points A and B.

\section{Conclusions}

(1) The fusion zone mainly consisted of equiaxed grains. In the as-welded condition, there were mainly $\alpha(\mathrm{Al}), \mathrm{MgZn}_{2}, \mathrm{Al}_{2} \mathrm{CuMg}$, and $\mathrm{Mg}_{32}(\mathrm{Al}, \mathrm{Zn})_{49}$ phases in the weldment. A fine equiaxed grain zone is formed along the fusion line. Grains in the HAZ grow larger, and some strengthening phases were precipitated in weld zone. The morphology and microstructure of the weldment improved to a certain extent after modification welding.

(2) Welded joint with a good appearance of weld was obtained by the proper welding procedure. Modification welding is advantageous to the mechanical properties of the welded joint. The maximum tensile strength of the welded joint reached $371.7 \mathrm{MPa}$. There are many dimples distributed on the fracture surface, and the joint dominantly presents the characteristics of ductile fracture.

(3) The simulated molten pool was well consistent with the experimental weld morphology. The reliability and accuracy of the simulation analysis are verified. In order to promote the precipitation of strengthening phases in the weld zone and increase the tensile strength of the joint, a suitable post weld heat treatment should be conducted to the welded joint.

Author Contributions: S.W.: methodology and funding acquisition, reviewing, and editing. Z.W. (Zheng Wang): investigation and writing original draft. C.Z.: supervision and project administration. Z.W. (Zhiguo Wang): resources and experimental preparation. All authors have read and agreed to the published version of the manuscript.

Funding: This project is supported by the Shanghai Aerospace Science and Technology Innovation Fund (Grant No. SAST2018-062), which is gratefully acknowledged.

Conflicts of Interest: The authors declare no conflict of interest.

\section{References}

1. Dursun, T.; Soutis, C. Recent developments in advanced aircraft aluminium alloys. Mater. Des. 2014, 56, 862-871. [CrossRef]

2. Williams, J.C.; Starke, E.A. Progress in structural materials for aerospace systems. Acta Mater. 2003, 51, 5775-5799. [CrossRef]

3. Dixit, M.; Mishra, R.S.; Sankaran, K.K. Structure-property correlations in Al 7050 and Al 7055 high-strength aluminum alloys. Mater. Sci. Eng. A 2008, 478, 163-172. [CrossRef]

4. Rometsch, P.A.; Zhang, Y.; Knight, S. Heat treatment of 7xxx series aluminium alloys-some recent developments. Trans. Nonferrous Met. Soc. China 2014, 24, 2003-2017. [CrossRef]

5. Mazzer, E.M.; Afonso, C.R.M.; Galano, M.; Kiminani, C.S.; Bolfarini, C. Microstructure evolution and mechanical properties of $\mathrm{Al}-\mathrm{Zn}-\mathrm{Mg}-\mathrm{Cu}$ alloy reprocessed by spray-forming and heat treated at peak aged condition. J. Alloys Compd. 2013, 579, 169-173. [CrossRef]

6. Ditta, A.; Wei, L.J.; Xu, Y.J.; Wu, S.J. Effect of hot extrusion and optimal solution treatment on microstructure and properties of spray-formed Al-11.3Zn-2.65Mg-1Cu alloy. J. Alloys Compd. 2019, 797, 558-565. [CrossRef] 
7. Kashaev, N.; Ventzke, V.; Çam, G. Prospects of laser beam welding and friction stir welding processes for aluminum airframe structural applications. J. Manuf. Process. 2018, 36, 571-600. [CrossRef]

8. Fukuda, T. Weldability of 7000 series aluminium alloy materials. Weld. Int. 2012, 26, 256-269. [CrossRef]

9. Hermann, R.; Birley, S.S.; Holdway, P. Liquation cracking in aluminium alloy welds. Mater. Sci. Eng. A 1996, 212, 247-255. [CrossRef]

10. Peng, X.Y.; Cao, X.W.; Xu, G.F.; Deng, Y.; Tang, L.; Yin, Z.M. Mechanical properties, corrosion behavior, and microstructures of a MIG-welded $7020 \mathrm{Al}$ alloy. J. Mater. Eng. Perform. 2016, 25, 1028-1040. [CrossRef]

11. Balasubramanian, V.; Ravisankar, V.; Reddy, G.M. Influences of pulsed current welding and post weld aging treatment on fatigue crack growth behavior of AA7075 aluminium alloy joints. Int. J. Fatigue 2008, 30, 405-416. [CrossRef]

12. Hassan, K.A.A.; Prangnell, P.B.; Norman, A.F.; Price, D.A.; Williams, S.W. Effect of welding parameters on nugget zone microstructure and properties in high strength aluminium alloy friction stir welds. Sci. Technol. Weld. Join. 2003, 8, 257-268. [CrossRef]

13. Wang, Q.Z.; Zhao, Z.X.; Zhao, Y.; Yan, K.; Liu, C.; Zhang, H. The strengthening mechanism of spray forming Al-Zn-Mg-Cu alloy by underwater friction stir welding. Mater. Des. 2016, 102, 91-99. [CrossRef]

14. Ola, O.T.; Doern, F.E. Fusion weldability studies in aerospace AA7075-T651 using high-power continuous wave laser beam techniques. Mater. Des. 2015, 77, 50-58. [CrossRef]

15. Enz, J.; Riekehr, S.; Ventzke, V.; Huber, N.; Kashaev, N. Fibre laser welding of high-alloyed Al-Zn-Mg-Cu alloys. J. Mater. Process. Technol. 2016, 237, 155-162. [CrossRef]

16. Enz, J.; Kumar, M.; Riekehr, S.; Ventzke, V.; Huber, N.; Kashaev, N. Mechanical properties of laser beam welded similar and dissimilar aluminum alloys. J. Manuf. Process. 2017, 29, 272-280. [CrossRef]

17. Holzer, M.; Hofmann, K.; Mann, V.; Hugger, F.; Roth, S.; Schmidt, M. Change of hot cracking susceptibility in welding of high strength aluminum alloy AA7075. Phys. Procedia 2016, 83, 463-471. [CrossRef]

18. Hu, B.; Richardson, I.M. Microstructure and mechanical properties of AA7075 (T6) hybrid Laser/GMA welds. Mater. Sci. Eng. A 2007, 459, 94-100. [CrossRef]

19. Zhan, X.H.; Yu, H.S.; Feng, X.S.; Pan, P.; Liu, Z.M. A comparative study on laser beam and electron beam welding of 5A06 aluminum alloy. Mater. Res. Express 2019, 6, 056563. [CrossRef]

20. Lacki, P.; Adamus, K. Numerical simulation of the electron beam welding process. Comput. Struct. 2011, 89, 977-985. [CrossRef]

21. Li, Y.J.; Zhao, Y.; Li, Q.; Wu, A.P.; Zhu, R.C.; Wang, G.Q. Effects of welding condition on weld shape and distortion in electron beam welded $\mathrm{Ti}_{2} \mathrm{AlNb}$ alloy joints. Mater. Des. 2017, 114, 226-233. [CrossRef]

22. Lin, D.C.; Wang, G.X.; Srivatsan, T.S. A mechanism for the formation of equiaxed grains in welds of aluminum-lithium alloy 2090. Mater. Sci. Eng. A 2003, 351, 304-309. [CrossRef]

23. Senkov, O.N.; Shagiev, M.R.; Senkova, S.V.; Miracle, D.B. Precipitation of $\mathrm{Al}_{3}(\mathrm{Sc}, \mathrm{Zr})$ particles in an $\mathrm{Al}-\mathrm{Zn}-\mathrm{Mg}-\mathrm{Cu}-\mathrm{Sc}-\mathrm{Zr}$ alloy during conventional solution heat treatment and its effect on tensile properties. Acta Mater. 2008, 56, 3723-3738. [CrossRef]

24. Sha, G.; Cerezo, A. Early-stage precipitation in Al-Zn-Mg-Cu alloy (7050). Acta Mater. 2004, 52, 4503-4516. [CrossRef]

25. Li, H.Y.; Gao, Z.H.; Yin, H.; Jiang, H.F.; Su, X.J.; Bin, J. Effects of Er and Zr additions on precipitation and recrystallization of pure aluminum. Scripta Mater. 2013, 68, 59-62. [CrossRef]

26. Ma, T.; den Ouden, G. Softening behavior of Al-Zn-Mg alloys due to welding. Mater. Sci. Eng. A 1999, 266, 198-204. [CrossRef]

27. Zhan, X.H.; Chen, J.C.; Liu, J.J.; Wei, Y.H.; Zhou, J.J.; Meng, Y. Microstructure and magnesium burning loss behavior of AA6061 electron beam welding joints. Mater. Des. 2016, 99, 449-458. [CrossRef]

28. Zhao, H.; Debroy, T. Weld metal composition change during conduction mode laser welding of aluminum alloy 5182. Metall. Mater. Trans. B 2001, 32, 163-172. [CrossRef]

Publisher's Note: MDPI stays neutral with regard to jurisdictional claims in published maps and institutional affiliations. 